\title{
Rapid heating thermal shock study of ultra high temperature ceramics using an in situ testing method
}

\author{
Rujie $\mathrm{HE}^{a, b, *}$, Zhaoliang QU ${ }^{a, b}$, Dong LIANG ${ }^{a, b}$ \\ ${ }^{a}$ Institute of Advanced Structure Technology, Beijing Institute of Technology, Beijing 100081, China \\ ${ }^{b}$ Beijing Key Laboratory of Lightweight Multi-functional Composite Materials and Structures, Beijing Institute of \\ Technology, Beijing 100081, China
}

Received: May 24, 2017; Revised: July 14, 2017; Accepted: July 14, 2017

(C) The Author(s) 2017. This article is published with open access at Springerlink.com

\begin{abstract}
In this paper, the rapid cooling thermal shock behaviors of $\mathrm{ZrB}_{2}-\mathrm{SiC}$ ceramics were measured using traditional water quenching method, and the rapid heating thermal shock behaviors of $\mathrm{ZrB}_{2}-\mathrm{SiC}$ ceramics were investigated using a novel in situ testing method. The measured critical thermal shock temperature difference for rapid cooling thermal shock was $373.6{ }^{\circ} \mathrm{C}$; however, the critical thermal shock temperature difference for rapid heating thermal shock of $\mathrm{ZrB}_{2}-\mathrm{SiC}$ ceramics was measured to be as high as $1497.2{ }^{\circ} \mathrm{C}$. The thermal stress distribution states after rapid cooling thermal shock and rapid heating thermal shock testing were analyzed using finite element analysis (FEA) method. The FEA results showed that there is a tensile stress existed on the surface for rapid cooling thermal shock, whereas there is a compressive stress existed on the surface for rapid heating thermal shock. The difference of thermal stress distribution resulted in the difference of the critical temperature difference for rapid cooling thermal shock and rapid heating thermal shock.
\end{abstract}

Keywords: ultra high temperature ceramics (UHTCs); thermal shock behavior; thermal stress; finite element analysis (FEA)

\section{Introduction}

Ultra high temperature ceramics (UHTCs) are promising candidates for use in thermal protection systems (TPS) and propulsion systems in hypersonic aerospace vehicles, owing to their ultra high melting temperatures, outstanding oxidation resistance, good chemical inertness, and high dimensional stability [1-4]. However, their intrinsic characteristics, such as low fracture toughness (premature failure due to brittle fracture) [5-7], poor thermal shock resistance [8-10], are still obstacles for them to be used widely, especially

\footnotetext{
* Corresponding author.
}

E-mail: herujie@bit.edu.cn for applications with high heat transfer and/or rapid environmental temperature changes. Therefore, the thermal shock behaviors of UHTCs have been intensively investigated in past decades [11-14], and how to improve the thermal shock resistance of UHTCs is one of the main challenges for engineering application.

As well known, the thermal shock resistance of ceramic is a major issue and important performance index for high temperature applications as the ceramic is susceptible to catastrophic failure under thermal stress owing to the temperature difference $[15,16]$. Usually, the thermal shock of UHTCs has two conditions: rapid cooling thermal shock and rapid heating thermal shock. At present, almost all experimental reports of UHTCs are about their rapid 
cooling thermal shock behaviors [11-14]. The rapid cooling thermal shock behaviors of UHTCs are always evaluated by water quenching method, in which the ceramic specimens are heated to a particular temperature and then quenched into a water bath. However, during the causative processes of UHTCs used in ultra high temperature applications, thermal shock also occurs under rapid heating conditions, e.g., nosecones and sharp leading edges of hypersonic aerospace vehicles endure a server rapid aerodynamic heating in a short time during their flight [17-19], and the intense ascending thermal shock will also lead to their failure. It is therefore very important and necessary to investigate not only the rapid cooling thermal shock behaviors, but also the rapid heating thermal shock behaviors of UHTCs.

The rapid cooling thermal shock behaviors are commonly tested using water quenching method, and the residual strengths are subsequently measured after quenching [11-14]. Nevertheless, testing methods for the rapid heating thermal shock behaviors mainly include laser heating [20], electron beam heating [21], oxyacetylene heating [18], radiant heating [22], plasma arc heating [23], arc-heating wind tunnel heating $[17,24]$, etc. However, these rapid heating thermal shock testing methods are either too complicated or costly. Moreover, the residual strengths always are $e x$ situ measured, even cannot be measured. Thus, a simple testing method for rapid heating thermal shock is necessary.

The aim of this paper is investigating and comparing the rapid cooling thermal shock behaviors and rapid heating thermal shock behaviors of UHTCs. In this study, the rapid cooling thermal shock behaviors of UHTCs were studied using a water quenching method, and the rapid heating thermal shock behaviors of $\mathrm{ZrB}_{2}-\mathrm{SiC}$ ceramics were investigated using a novel in situ testing method. The differences of the critical temperature difference and thermal stress distribution between the rapid cooling thermal shock and rapid heating thermal shock of UHTCs were discussed and compared. This novel method can give some new insight of the thermal shock behaviors of UHTCs.

\section{Experimental procedure}

\section{1 Raw materials}

Commercial $\mathrm{ZrB}_{2}$ powders ( $2 \mu \mathrm{m}$; > 99.5\%; New Metal Materials Technology Co., Ltd., Beijing, China) and SiC powders $(0.5 \mu \mathrm{m} ;>99.5 \%$; New Metal Materials Technology Co., Ltd., Beijing, China) were used as raw materials. $\mathrm{ZrB}_{2}-20$ vol\% $\mathrm{SiC}$ ultra high temperature ceramics were prepared using hot-pressing at $1950{ }^{\circ} \mathrm{C}$ for $1 \mathrm{~h}$ under a uniaxial pressure of $30 \mathrm{MPa}$. Detailed fabrication process was reported in our previous study [25-27], and typical properties of this UHTC were listed in Table 1.

The microstructures of the polished surface and fracture surface of the as-prepared hot-pressed $\mathrm{ZrB}_{2}-\mathrm{SiC}$ ceramic are presented in Fig. 1. From these SEM images, the hot-pressed $\mathrm{ZrB}_{2}-\mathrm{SiC}$ ceramic is fully dense, and no obvious residual porosity is detected. The $\mathrm{SiC}$ particles, which are represented by the majority of the dark features, are homogeneously dispersed in the $\mathrm{ZrB}_{2}$ matrix and no obvious agglomeration is detected.

$36 \mathrm{~mm} \times 4 \mathrm{~mm} \times 3 \mathrm{~mm} \quad$ (length $\times$ width $\times$ thickness) testing bars were cut from the hot-pressed $\mathrm{ZrB}_{2}-\mathrm{SiC}$ and used for rapid cooling thermal shock and rapid heating thermal shock testing. A minimum number of five specimens were tested for each condition.

\section{2 Rapid cooling thermal shock and rapid heating thermal shock testing}

In this study, the rapid cooling thermal shock behaviors of UHTCs were studied using a water quenching method; specifically, the rapid heating thermal shock behaviors of the $\mathrm{ZrB}_{2}-\mathrm{SiC}$ ceramic were investigated using a self-assembled in situ testing system. And the results of the rapid heating thermal shock behaviors were compared to those of the rapid cooling thermal shock behaviors by traditional water quenching method.

Figure 2(a) shows the rapid cooling thermal shock behavior testing by traditional water quenching method. During this testing, the $\mathrm{ZrB}_{2}-\mathrm{SiC}$ ceramic bar was firstly heated in a Muffle furnace in air atmosphere up to a target temperature, and then held for $10 \mathrm{~min}$ to

Table 1 Mechanical and thermo-physical properties of $\mathrm{ZrB}_{2}-\mathbf{2 0} \% \mathrm{SiC}$ ceramic

\begin{tabular}{|c|c|c|c|c|c|c|}
\hline Temperature (K) & $\begin{array}{l}\text { Density } \\
\left(\mathrm{kg} / \mathrm{m}^{3}\right)\end{array}$ & $\begin{array}{l}\text { Specific heat } \\
(\mathrm{J} /(\mathrm{kg} \cdot \mathrm{K}))\end{array}$ & $\begin{array}{l}\text { Thermal conductivity } \\
(\mathrm{W} /(\mathrm{m} \cdot \mathrm{K}))\end{array}$ & $\begin{array}{c}\text { Thermal } \\
\text { expansion } \\
\left(10^{-6} / \mathrm{K}\right)\end{array}$ & $\begin{array}{c}\text { Young's } \\
\text { modulus (GPa) }\end{array}$ & Possion's ratio \\
\hline 298 & 5514 & 806 & 119.036 & 3.86 & 248.2 & 0.165 \\
\hline 1073 & 5514 & 715 & 73.703 & 4.68 & 191.6 & 0.165 \\
\hline 1473 & 5514 & 772 & 61.673 & 5.05 & 118.7 & 0.165 \\
\hline 1873 & 5514 & 820 & 55.856 & 5.85 & 33.26 & 0.165 \\
\hline
\end{tabular}



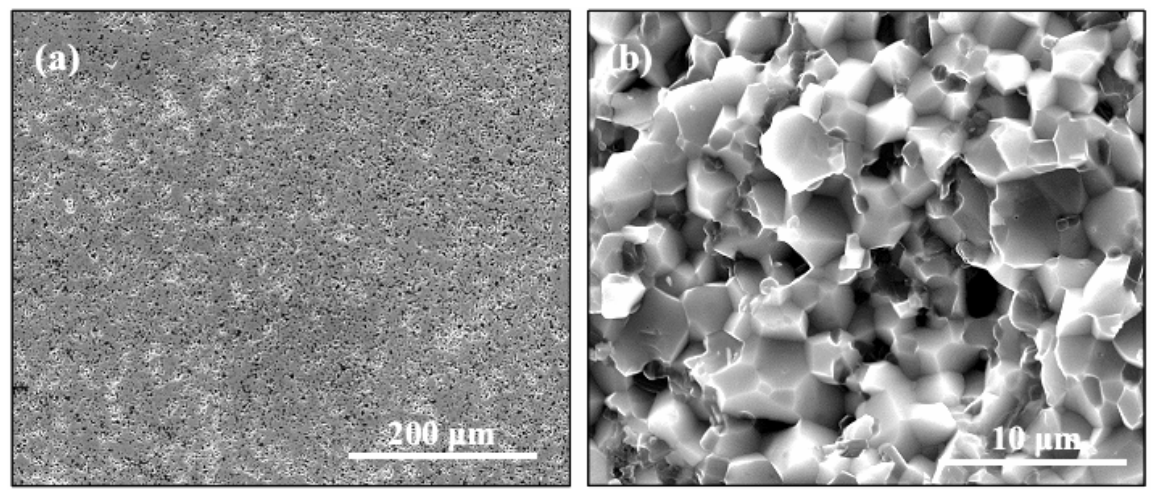

Fig. 1 (a) Polished surface and (b) fracture surface of the hot-pressed $\mathrm{ZrB}_{2}-\mathrm{SiC}$ ceramic.
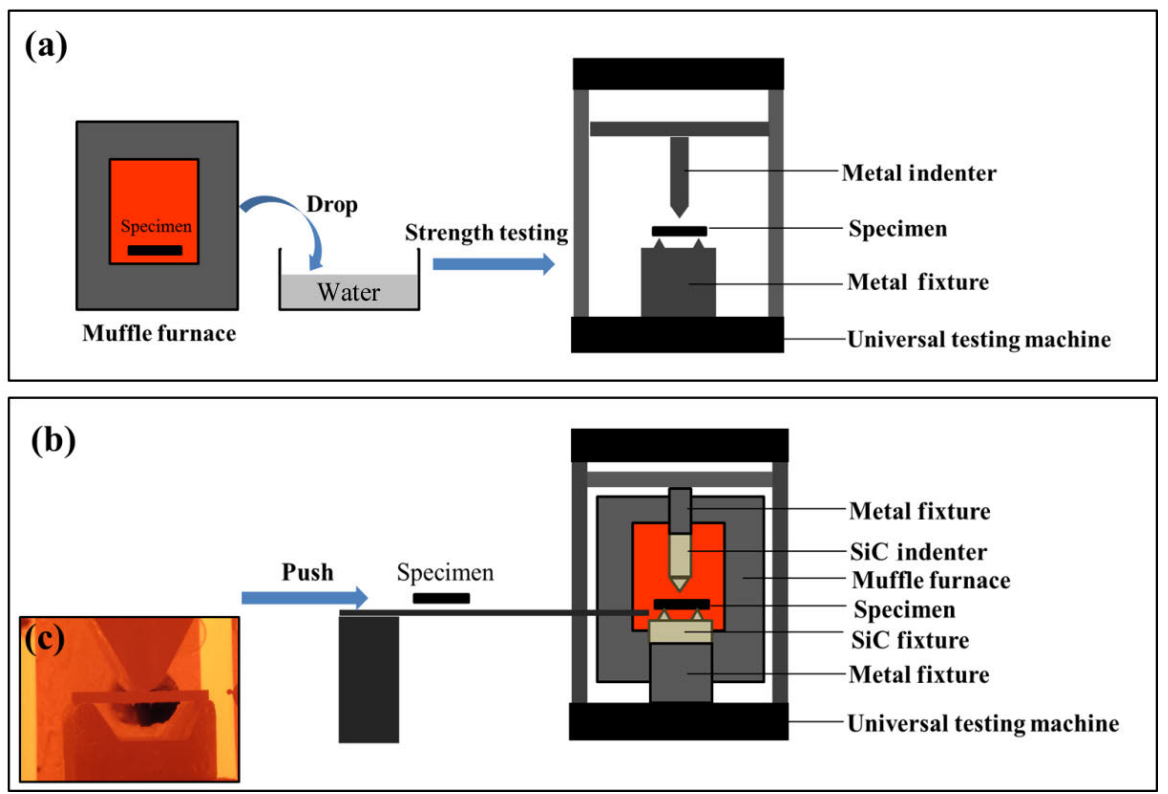

Fig. 2 Diagrammatic sketches of (a) the rapid cooling thermal shock behavior testing by traditional water quenching method, (b) the rapid heating thermal shock behavior testing by a self-assembled in situ testing method, and (c) photo of the in situ strength testing (inset).

eliminate any temperature gradient effect. The target temperatures of the furnace were set as 200, 300, 400, $500,600,700$, and $800{ }^{\circ} \mathrm{C}$. Subsequently, the testing bar was dropped into a water bath in less than $1 \mathrm{~s}$. The temperature of the ice-cold water bath was set as $0{ }^{\circ} \mathrm{C}$. The strength before and after water quenching was measured by a three-point bending test (WDW-100, Changchun Fangrui Technology Co., Ltd., China), using a loading span of $30 \mathrm{~mm}$ with a crosshead speed of $0.5 \mathrm{~mm} / \mathrm{min}$. Detailed water quenching method for rapid cooling thermal shock testing was reported elsewhere [11].

Figure 2(b) presents the rapid heating thermal shock behavior testing using a self-assembled in situ testing system. In this system, the Muffle furnace was firstly heated to a target temperature in air atmosphere, which was set as 225 to $1625{ }^{\circ} \mathrm{C}$ with an interval of $200{ }^{\circ} \mathrm{C}$. Then, the $\mathrm{ZrB}_{2}-\mathrm{SiC}$ ceramic bar was quickly pushed into the furnace through a pre-laying $\mathrm{SiC}$ slide in less than $1 \mathrm{~s}$. The $\mathrm{ZrB}_{2}-\mathrm{SiC}$ ceramic bar was subsequently held for $10 \mathrm{~min}$ in the furnace to eliminate any temperature gradient effect. The original strength before rapid heating was measured. And the residual strength after rapid heating was in situ tested, as shown in Fig. 2(c). For this in situ testing system, both the fixture and indenter were made of $\mathrm{SiC}$ ceramic. The loading span and crosshead speed were also set as $30 \mathrm{~mm}$ and $0.5 \mathrm{~mm} / \mathrm{min}$, respectively.

\section{3 Characterizations}

The microstructures of the $\mathrm{ZrB}_{2}-\mathrm{SiC}$ ceramic before and after testing were observed using a scanning 
electron microscope (SEM, S-4800, Hitachi, Japan). Finite element analysis (FEA) method was used to simulate the thermal stress distribution in the specimen after testing by the commercial finite element package ABAQUS (Abaqus theory manual. Version 6.13). Considering the geometric configuration of the specimens, a three-dimensional finite element model was constructed to simulate the thermal stress response in the thermal shock experiments. The specimen was meshed with 27648 eight-node thermally coupled brick, trilinear displacement and temperature elements. A convergent solution with respect to the number of elements was confirmed. For rapid cooling thermal shock analysis, the initial temperature of the whole specimen was fixed at the setting temperatures in the rapid cooling thermal shock experiments. The whole surfaces of specimens were fixed at $0{ }^{\circ} \mathrm{C}$. For rapid heating thermal shock analysis, the initial temperature of the whole specimen was fixed at $25{ }^{\circ} \mathrm{C}$. The whole surfaces of specimens were fixed at the setting temperatures in the rapid heating thermal shock experiments. The mechanical and thermo-physical property data of the $\mathrm{ZrB}_{2}-\mathrm{SiC}$ ceramic used for FEA are measured before this study and listed in Table 1 .

\section{Results}

The original room temperature flexural strength $(\sigma)$ of the as-prepared $\mathrm{ZrB}_{2}-\mathrm{SiC}$ ceramic was measured to be 299.4 $\pm 13.5 \mathrm{MPa}$. Figures 3(a) and 3(b) show the residual flexural strength $\left(\sigma_{\mathrm{r}}\right)$ of the $\mathrm{ZrB}_{2}-\mathrm{SiC}$ ceramic after the rapid cooling and rapid heating thermal shock testing with increasing the temperature difference $(\Delta T)$.

\section{1 Rapid cooling thermal shock}

For rapid cooling thermal shock testing, as the temperature difference $(\Delta T)$ increases up to $300{ }^{\circ} \mathrm{C}$, the flexural strength shows no obvious change compared with the original room temperature flexural strength. The residual flexural strength is $301.7 \pm 8.5$ and $306.3 \pm 23 \mathrm{MPa}$, respectively, at the temperature difference $(\Delta T)$ of 200 and $300{ }^{\circ} \mathrm{C}$. It presents a slight increase in strength, which might be attributed to the measure deviation. When $\Delta T$ is higher than $300{ }^{\circ} \mathrm{C}$, the flexural strength of the $\mathrm{ZrB}_{2}-\mathrm{SiC}$ ceramic decreases sharply. The residual flexural strength is $178.4 \pm 28.5$,
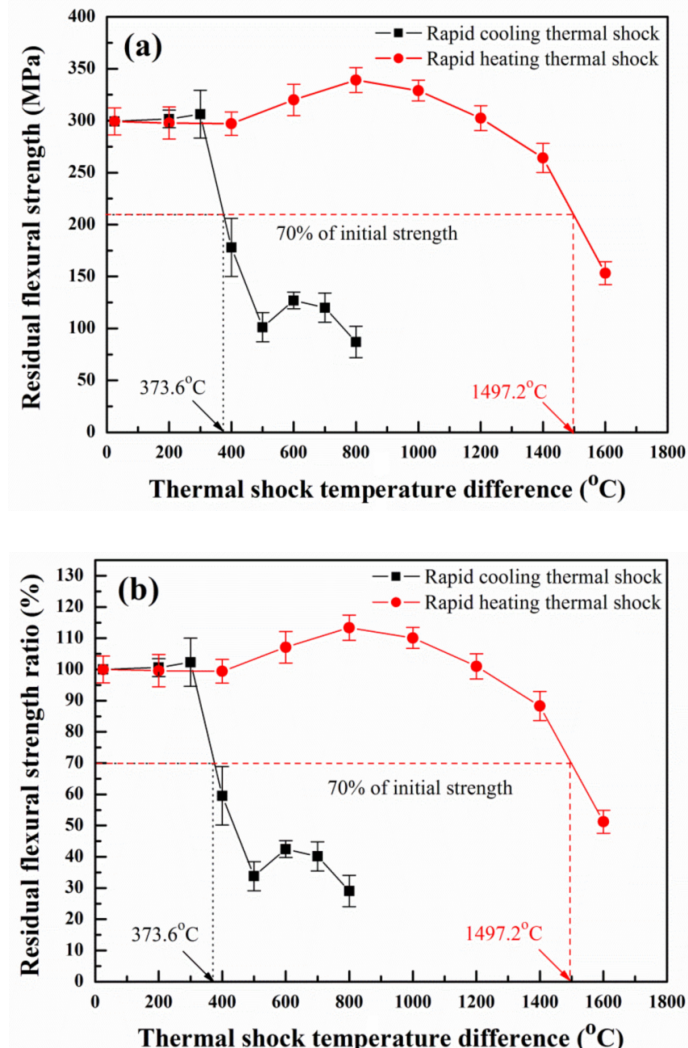

Fig. 3 (a) Residual flexural strength and (b) residual flexural strength ratio of $\mathrm{ZrB}_{2}-\mathrm{SiC}$ ceramic after rapid cooling and rapid heating thermal shock.

$101.2 \pm 14.3, \quad 127.2 \pm 8.1,120.8 \pm 14.5$, and $87.5 \pm 15.2$ $\mathrm{MPa}$ at the temperature difference $(\Delta T)$ of 400,500 , 600,700 , and $800{ }^{\circ} \mathrm{C}$, respectively. It is found that, when $\Delta T$ is higher than $300{ }^{\circ} \mathrm{C}$, the flexural strength of the $\mathrm{ZrB}_{2}-\mathrm{SiC}$ ceramic is to follow Hasselman's theory which predicts a sharp drop in strength at a critical thermal shock temperature difference $\left(\Delta T_{\mathrm{c}}\right)$ $[28,29]$. Typically, the critical temperature difference $\left(\Delta T_{\mathrm{c}}\right)$ is identified using a liner interpolation between points that first reduces the average flexural strength of the quenched bars by more than $30 \%$ of the mean strength of the as-prepared ceramic as described in ASTM C1525-04 [30]. In this study, the critical temperature difference for rapid cooling thermal shock $\left(\Delta T_{\mathrm{c}}^{\text {cooling }}\right.$ ) is measured to be $373.6^{\circ} \mathrm{C}$, which is lower than reported in literature. Wang et al. [31] prepared $\mathrm{ZrB}_{2}-20 \mathrm{vol} \% \mathrm{SiC}$ ceramic, and its critical temperature difference for rapid cooling thermal shock $\left(\Delta T_{\mathrm{c}}^{\text {cooling }}\right)$ was about $469{ }^{\circ} \mathrm{C}$. The difference between our study and literature can be attributed to the raw materials and processing parameters. Zimmernann et al. [30] also 
reported the thermal shock resistance of $\mathrm{ZrB}_{2}-30 \mathrm{vol} \%$ $\mathrm{SiC}$ ceramic, and its critical temperature difference for rapid cooling thermal shock ( $\Delta T_{\mathrm{c}}^{\text {cooling }}$ ) was about $395{ }^{\circ} \mathrm{C}$, which was attributed to the more toughening mechanism of more $\mathrm{SiC}$ particles. The abnormal strength growth at $600{ }^{\circ} \mathrm{C}$ is attributed to the oxidation-induced crack healing, which starts to lose its effect above $800{ }^{\circ} \mathrm{C}[30,31]$.

\section{2 Rapid heating thermal shock}

In ASTM C1525-04 standard, the critical temperature difference is defined as the temperature difference that will cause a $30 \%$ drop in the average flexural strength. The residual strength is tested at room temperature as a criterion to define the thermal shock critical temperature difference for the rapid cooling thermal shock testing. Therefore, in our paper, for rapid heating thermal shock testing, we tested the residual strength at high temperatures in situ. That is to say, the high temperature of the ceramic was tested after rapid heating thermal shock, and we think this high temperature strength equals to residual strength after thermal shock. In previous method, the strengths of the ceramic materials after thermal shock testing were either non-measurable or ex situ measured [17-24]. In our study, the residual strengths of the $\mathrm{ZrB}_{2}-\mathrm{SiC}$ ceramic after the rapid heating were in situ measured using a self-assembled simple testing equipment, as shown in Fig. 1(b). Using this novel method, the residual strengths were tested. When the temperature difference $(\Delta T)$ is 200 and $400{ }^{\circ} \mathrm{C}$, the flexural strength shows no obvious change compared with the original room temperature flexural strength, which is similar with rapid cooling thermal shock. When $\Delta T$ is in the range of $400-800{ }^{\circ} \mathrm{C}$, the strength is found to be slightly improved. However, the flexural strength of the $\mathrm{ZrB}_{2}-\mathrm{SiC}$ ceramic exhibits sharp decrease when $\Delta T$ is above $800{ }^{\circ} \mathrm{C}$. Thus, the temperature at which the ceramic possesses $70 \%$ residual flexural strength could be obtained. The critical temperature difference for rapid heating thermal shock $\left(\Delta T_{\mathrm{c}}^{\text {heating }}\right)$ is measured to be as high as $1497.2^{\circ} \mathrm{C}$, which is far greater than $\Delta T_{\mathrm{c}}^{\text {cooling }}\left(373.6^{\circ} \mathrm{C}\right)$.

\section{Discussion}

The differences of the critical temperature difference
( $\Delta T_{\mathrm{c}}$ ) existing between rapid cooling thermal shock and rapid heating thermal shock are attributed to the thermal stress distribution in the specimens after testing. Unfortunately, the thermal stress distribution is difficult to measure accurately by experimental methods. Numerical approach is an effective method for stress distribution analysis. In this study, finite element analysis (FEA) method was used to simulate and evaluate the thermal stress distribution in the specimen after thermal shock testing.

Figure 4 shows the thermal stress distribution in the specimens after rapid cooling thermal shock testing. The simulated thermal stress distribution in the specimen after rapid cooling thermal shock testing at the thermal shock temperature difference $(\Delta T)$ of $400{ }^{\circ} \mathrm{C}$ is shown in Fig. 4(a). In order to see clearly, half of the specimen was cut and the thermal stress distribution is presented in detail in Fig. 4(d). It is found that the maximum stress at $\Delta T=400{ }^{\circ} \mathrm{C}$ is about 36.9 MPa, which is a tensile stress of S33 located on the specimen surface. Moreover, the maximum stress at $\Delta T=600$ and $800{ }^{\circ} \mathrm{C}$ is about $41.8 \mathrm{MPa}$ (Figs. 4(b) and 4(e)) and 46.9 MPa (Figs. 4(c) and 4(f)), respectively, which are both tensile stress of S33 located on the specimen surface. It is observed that there is some deformation at different temperatures, which is attributed to the difference of thermal shrinkage at different temperatures.

During rapid cooling thermal shock, the temperature on the surface drops more quickly than that of the inner of the specimen. Therefore, cracks yield on the surface of the specimen. On one hand, the thermal deformation on the surface is higher than the inner of the specimen because the surface suffers a higher temperature drop. Hence, there is a tensile stress existed on the surface. On the other hand, the $\mathrm{ZrB}_{2}-\mathrm{SiC}$ ceramic endures oxidation in the furnace, which results in a thin oxidation layer onto the surface. The mismatch of the thermal expansion coefficients between the $\mathrm{ZrB}_{2}-\mathrm{SiC}$ ceramic matrix and the oxidation layer results in thermal residual stress during cooling from elevated temperatures to lower temperatures. Tensile stress induces the crack propagation, finally resulting in strength loss after testing. When the thermal shock temperature difference $(\Delta T)$ is 200 and $400{ }^{\circ} \mathrm{C}$, the residual strength shows no obvious drop, because the temperature difference is relatively small (as shown in Fig. 3). When the rapid cooling thermal shock temperature difference is further improved, the surface 
(a)

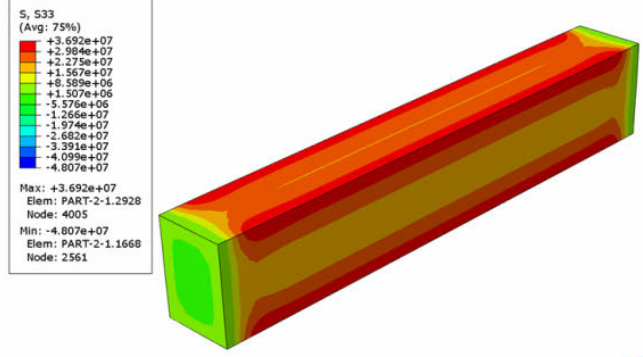

(b)

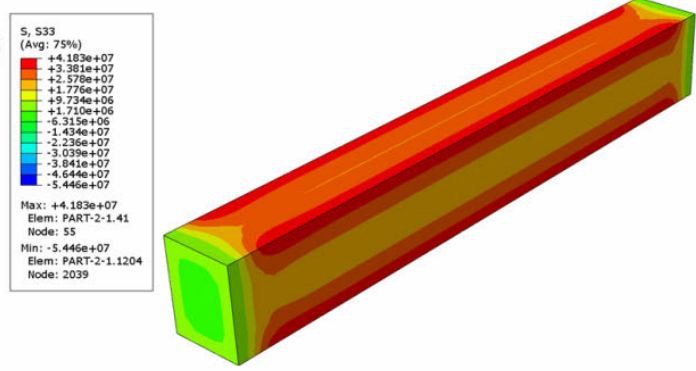

(c)

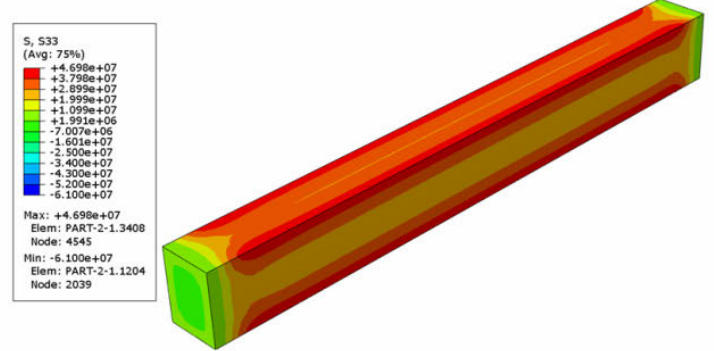

(d)

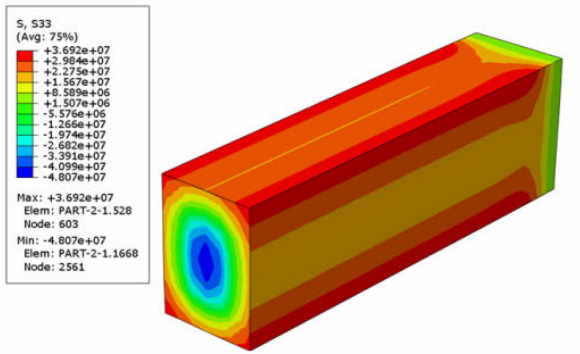

(e)

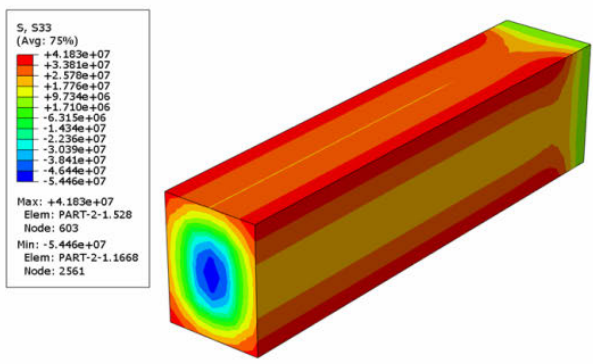

(f)

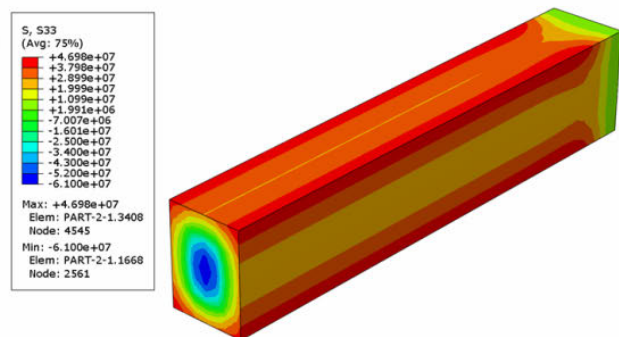

Fig. 4 Thermal stress distribution after rapid cooling thermal shock testing: (a, d) $\Delta T=400{ }^{\circ} \mathrm{C},(\mathrm{b}, \mathrm{e}) \Delta T=600{ }^{\circ} \mathrm{C}$, and (c, f) $\Delta T=800{ }^{\circ} \mathrm{C}$.

tensile stress rises correspondingly. FEA analysis results indicate the tensile stress is 41.8 and $46.9 \mathrm{MPa}$ at $\Delta T=600$ and $800{ }^{\circ} \mathrm{C}$, respectively. The tensile stress grows, the surface cracks are "pulled" to propagation, and thus the flexural strength of the ceramic specimen declines significantly. In this paper, the critical thermal shock temperature difference $\left(\Delta T_{\mathrm{c}}\right)$ of the $\mathrm{ZrB}_{2}-\mathrm{SiC}$ ceramic is determined using water quenching method. And the measured critical thermal shock temperature difference for rapid cooling thermal shock $\Delta T_{\mathrm{c}}^{\text {cooling }}$ is defined as the temperature at which its strength is $70 \%$ of the room temperature strength, which is determined using linear interpolation of the residual strength values according to ASTM C1525-04 standard (Standard Test Method for Determination of Thermal Shock Resistance for Advanced Ceramics by Water Quenching, http://www.astm.org/DATABASE.CART/ HISTORICAL/C1525-04.htm). $\Delta T_{\mathrm{c}}^{\text {cooling }}$ is measured to be $373.6{ }^{\circ} \mathrm{C}$.

However, for rapid heating thermal shock, the ceramic specimen is suddenly heated to an elevated temperature. During this rapid process, the surface of the ceramic specimen suffers a more sudden temperature increasing than that of the inner of the specimen. That is to say, a compressive stress appears on the surface of the ceramic specimen, owing to the coupling effect of thermal gradient and the mismatch of the thermal expansion coefficients between the $\mathrm{ZrB}_{2}-\mathrm{SiC}$ ceramic matrix and the oxidation layer. Compression stress shows an inhibition effect on crack propagation. It is because of the existing of the surface compression stress that the cracks grow slowly and the critical thermal shock temperature difference for rapid heating thermal shock $\left(\Delta T_{\mathrm{c}}^{\text {heating }}\right)$ is much higher than $\Delta T_{\mathrm{c}}^{\text {cooling }}$.

FEA analysis indicates the thermal stress distribution after rapid heating thermal shock testing, as shown in Fig. 5. The simulated thermal stress distribution in the specimen after rapid heating thermal shock testing at the thermal shock temperature difference $(\Delta T)$ of $400{ }^{\circ} \mathrm{C}$ is shown in Fig. 5(a). It is also observed that there is some deformation at different temperatures, which is attributed to the difference of thermal expansion at different temperatures. Also, in order to 
(a)

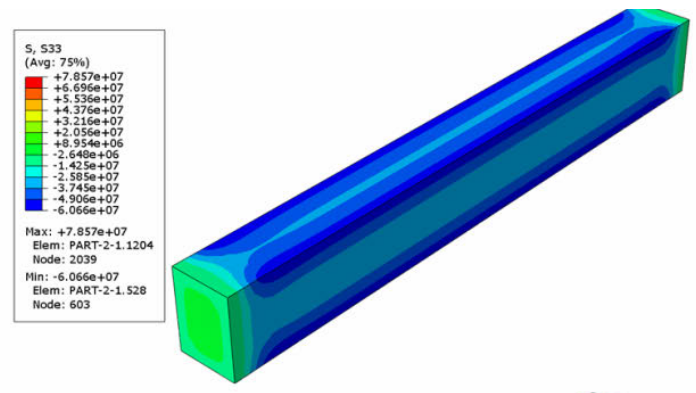

(b)
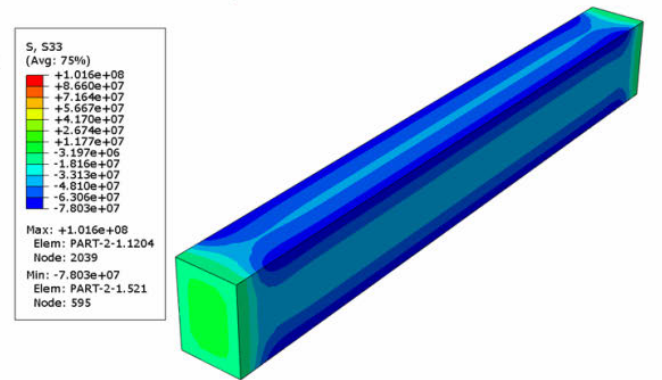

(c)

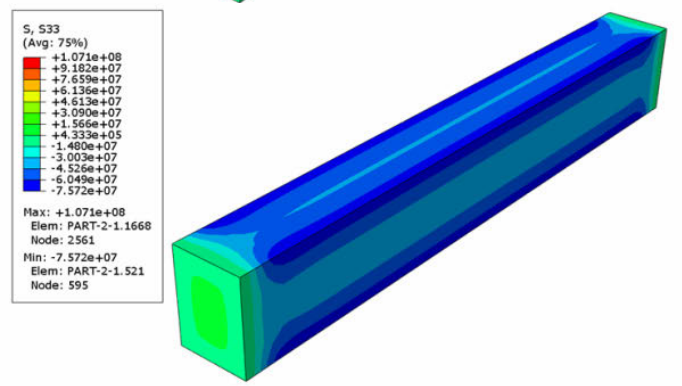

(d)

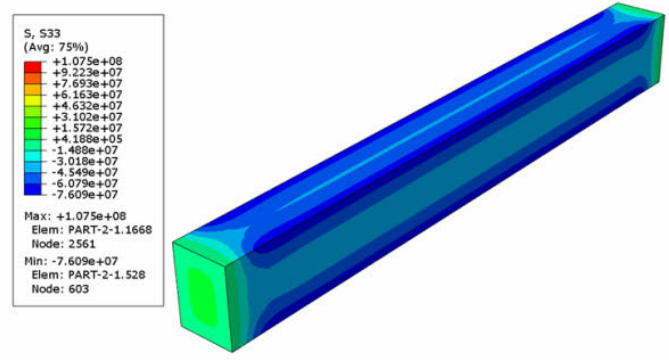

(e)

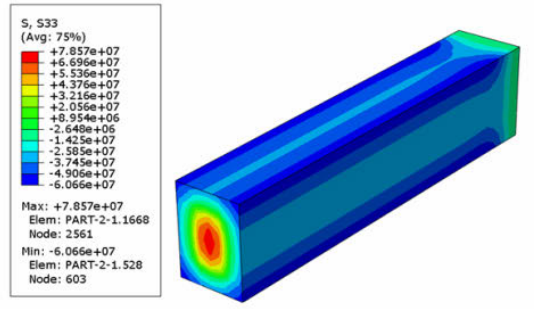

(f)

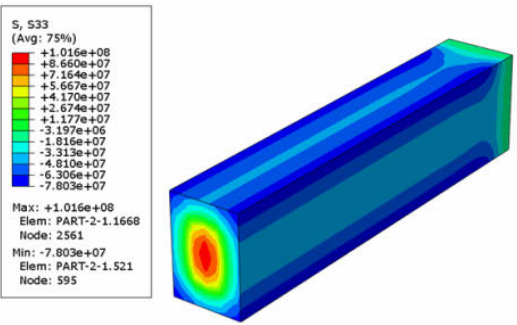

(g)

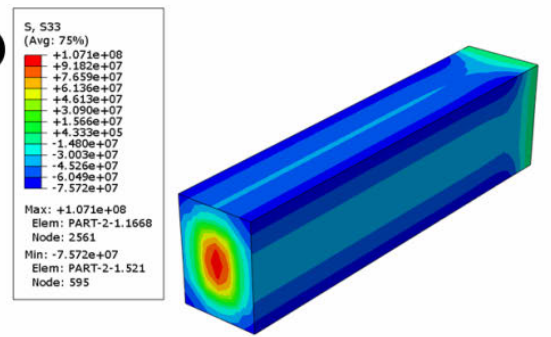

(h)

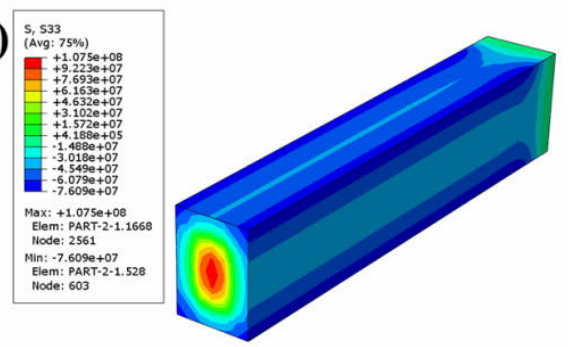

Fig. 5 Thermal stress distribution after rapid heating thermal shock testing: (a, e) $\Delta T=400{ }^{\circ} \mathrm{C},(\mathrm{b}, \mathrm{f}) \Delta T=800{ }^{\circ} \mathrm{C},(\mathrm{c}, \mathrm{g}) \Delta T=$ $1200{ }^{\circ} \mathrm{C}$, and $(\mathrm{d}, \mathrm{h}) \Delta T=1600{ }^{\circ} \mathrm{C}$.

see clearly, half of the specimen was cut and the thermal stress distribution is presented in detail in Fig. 5(e). It is found that the maximum stress at $\Delta T=400{ }^{\circ} \mathrm{C}$ is about $78.6 \mathrm{MPa}$, which is a compressive stress of $\mathrm{S} 33$ located on the specimen surface. From the FEA results, the maximum surface compression stress at $\Delta T=400,800$, 1200 , and $1600{ }^{\circ} \mathrm{C}$ is simulated to be $78.6,101.6,107.1$, and $110.5 \mathrm{MPa}$, respectively.

During rapid heating thermal shock, the temperature on the surface rises more quickly than that of the inner of the specimen. The thermal deformation on the surface is higher than the inner of the specimen because the surface suffers a higher temperature rise. Hence, there is a compressive stress existed on the surface. On the other hand, the $\mathrm{ZrB}_{2}-\mathrm{SiC}$ ceramic endures oxidation in the furnace, which results in a thin oxidation layer onto the surface. The mismatch of the thermal expansion coefficients between the $\mathrm{ZrB}_{2}-\mathrm{SiC}$ ceramic matrix and the oxidation layer results in thermal residual stress during heating from low temperatures to lower elevated temperatures. Compression stress shows an inhibition effect on crack propagation. The compressive stress "pushes" the cracks and prevents it from propagation. In this paper, the critical thermal shock temperature difference $\left(\Delta T_{\mathrm{c}}\right)$ of the $\mathrm{ZrB}_{2}-\mathrm{SiC}$ ceramic is determined by a novel in situ testing method. 
And the measured critical thermal shock temperature difference for rapid heating thermal shock $\Delta T_{\mathrm{c}}^{\text {heating }}$ is defined as the temperature at which its strength is $70 \%$ of the room temperature strength. $\Delta T_{\mathrm{c}}^{\text {heating }}$ is measured to be $1497.2^{\circ} \mathrm{C}$, which is much higher than $\Delta T_{\mathrm{c}}^{\text {cooling }}$.

\section{Conclusions}

In summary, a novel in situ testing method for rapid heating thermal shock testing of ultra high temperature ceramics was developed. The principle of this testing method is that a UHTC testing bar is rapidly put into a target high temperature environment, and the residual strength is in situ measured. Using this in situ testing method, rapid heating thermal shock behavior of $\mathrm{ZrB}_{2}-\mathrm{SiC}$ ceramic was studied and compared with its rapid cooling thermal shock behavior using traditional water quenching method. The critical thermal shock temperature difference for rapid heating thermal shock $\left(\Delta T_{\mathrm{c}}^{\text {heating }}\right.$ ) of $\mathrm{ZrB}_{2}-\mathrm{SiC}$ ceramic was measured to be as high as $1497.2{ }^{\circ} \mathrm{C}$, according to ASTM C1525-04 standard; however, the measured critical thermal shock temperature difference for rapid cooling thermal shock $\left(\Delta T_{c}^{\text {cooling }}\right.$ ) was $373.6{ }^{\circ} \mathrm{C}$, which was much lower than $\Delta T_{\mathrm{c}}^{\text {heating }}$. The difference of the critical temperature difference $\left(\Delta T_{\mathrm{c}}\right)$ existing between rapid cooling thermal shock and rapid heating thermal shock is attributed to the thermal stress distribution in the specimens after testing. For traditional rapid cooling thermal shock, there was a tensile stress existed on the surface. Whereas, for traditional rapid heating thermal shock, there was a compressive stress existed on the surface. The differences of the thermal stress distribution on the specimen resulted in the huge difference between $\Delta T_{\mathrm{c}}^{\text {cooling }}$ and $\Delta T_{\mathrm{c}}^{\text {heating }}$. This novel method and interesting results can give some new insight of the thermal shock behavior of UHTCs.

\section{Acknowledgements}

The authors sincerely thank the financial supports from the National Natural Science Foundation of China (No. 11402003) and Young Elite Scientist Sponsorship (YESS) Program by CAST (No. 2015QNRC001).

\section{References}

[1] Yu L, Feng Y, Yang J, et al. Mechanical and thermal physical properties, and thermal shock behavior of $\left(\mathrm{ZrB}_{2}+\mathrm{SiC}\right)$ reinforced $\mathrm{Zr}_{3}[\mathrm{Al}(\mathrm{Si})]_{4} \mathrm{C}_{6}$ composite prepared by in situ hot-pressing. $J$ Alloys Compd 2015, 619: 338-344.

[2] Hong W, Gui $\mathrm{K}, \mathrm{Hu} \mathrm{P}$, et al. Preparation and characterization of high-performance $\mathrm{ZrB}_{2}-\mathrm{SiC}-\mathrm{C}_{\mathrm{f}}$ composites sintered at $1450{ }^{\circ} \mathrm{C} . J \mathrm{Adv}$ Ceram 2017, 6: 110-119.

[3] Saunders T, Grasso S, Reece MJ. Limiting oxidation of $\mathrm{ZrB}_{2}$ by application of an electric field across its oxide scale. J Alloys Compd 2015, 653: 629-635.

[4] Jayaseelan DD, Zapata-Solvas E, Chater RJ, et al. Structural and compositional analyses of oxidised layers of $\mathrm{ZrB}_{2}$-based UHTCs. J Eur Ceram Soc 2015, 35: 4059-4071.

[5] Lin J, Zhang X, Wang Z, et al. Microstructure and mechanical properties of hot-pressed $\mathrm{ZrB}_{2}-\mathrm{SiC}-\mathrm{ZrO}_{2 \mathrm{f}}$ ceramics with different sintering temperatures. Mater Design 2012, 34: 853-856.

[6] Zhou S, Wang Z, Zhang W. Effect of graphite flake orientation on microstructure and mechanical properties of $\mathrm{ZrB}_{2}-\mathrm{SiC}$-graphite composite. J Alloys Compd 2009, 485: 181-185.

[7] Squire TH, Marschall J. Material property requirements for analysis and design of UHTC components in hypersonic applications. J Eur Ceram Soc 2010, 30: 2239-2251.

[8] Yu CH, Bird MW, Huang CW, et al. Micromechanics modeling of creep fracture of zirconium diboride-silicon carbide composites at $1400-1700{ }^{\circ} \mathrm{C}$. J Eur Ceram Soc 2014, 34: 4145-4155.

[9] Wang Z, Qu Q, Wu Z, et al. The thermal shock resistance of the $\mathrm{ZrB}_{2}-\mathrm{SiC}-\mathrm{ZrC}$ ceramic. Mater Design 2011, 32: 3499-3503.

[10] Zhou S, Wang Z, Sun X, et al. Microstructure, mechanical properties and thermal shock resistance of zirconium diboride containing silicon carbide ceramic toughened by carbon black. Mater Chem Phys 2010, 122: 470-473.

[11] He R, Zhang R, Pei Y, et al. Two-step hot pressing of bimodal micron/nano- $\mathrm{ZrB}_{2}$ ceramic with improved mechanical properties and thermal shock resistance. Int $J$ Refract Met H 2014, 46: 65-70.

[12] Parthasarathy TA, Petry MD, Cinibulk MK, et al. Thermal and oxidation response of UHTC leading edge samples exposed to simulated hypersonic flight conditions. $J \mathrm{Am}$ Ceram Soc 2013, 96: 907-915.

[13] Li D, Li W, Zhang W, et al. Thermal shock resistance of ultra-high temperature ceramics including the effects of thermal environment and external constraints. Mater Design 2012, 37: 211-214.

[14] Wang Y, Liang J, Han W, et al. T Mechanical properties and thermal shock behavior of hot-pressed $\mathrm{ZrB}_{2}-\mathrm{SiC}-\mathrm{AlN}$ composites. J Alloys Compd 2009, 475: 762-765.

[15] Lu TJ, Fleck NA. The thermal shock resistance of solids. Acta Mater 1998, 46: 4755-4768.

[16] Swain MV. R-curve behavior and thermal shock resistance of ceramics. J Am Ceram Soc 1990, 73: 621-628.

[17] Zhang X, Hu P, Han J, et al. Ablation behavior of $\mathrm{ZrB}_{2}-\mathrm{SiC}$ ultra high temperature ceramics under simulated 
atmospheric re-entry conditions. Compos Sci Technol 2008, 68: $1718-1726$.

[18] Jin X, He R, Zhang X, et al. Ablation behavior of $\mathrm{ZrB}_{2}-\mathrm{SiC}$ sharp leading edges. J Alloys Compd 2013, 566: 125-130.

[19] Monteverde F, Savino R. $\mathrm{ZrB}_{2}-\mathrm{SiC}$ sharp leading edges in high enthalpy supersonic flows. J Am Ceram Soc 2012, 95 : 2282-2289.

[20] Jian CY, Hashida T, Takahashi H, et al. Thermal shock and fatigue resistance evaluation of functionally graded coating for gas turbine blades by laser heating method. Compos Eng 1995, 5: 879-889.

[21] Jin H, Meng S, Zhu Y, et al. Effect of environment atmosphere on thermal shock resistance of the $\mathrm{ZrB}_{2}-\mathrm{SiC}$-graphite composite. Mater Design 2013, 50: 509-514.

[22] Schneider GA, Petzow G. Thermal shock testing of ceramic materials-A new testing method. J Am Ceram Soc 1991, 74: $98-102$.

[23] Zhang X-H, Han J-C, He X-D, et al. Ablation-resistance of combustion synthesized $\mathrm{TiB}_{2}-\mathrm{Cu}$ cermet. J Am Ceram Soc 2005, 88: 89-94.

[24] Sant YL, Marchand M, Millan P, et al. An overview of infrared thermography techniques used in large wind tunnels. Aerosp Sci Technol 2002, 6: 355-366.

[25] Wei K, He RJ, Cheng XM, et al. A lightweight, high compression strength ultra high temperature ceramic corrugated panel with potential for thermal protection system applications. Mater Design 2015, 66: 552-556.

[26] Wang G, Xiao P, Huang Z, et al. Brazing of $\mathrm{ZrB}_{2}-\mathrm{SiC}$ ceramic with amorphous CuTiNiZr filler. Ceram Int 2016, 42: 5130-5135.

[27] Qu Z, He R, Wei K, et al. Pre-oxidation temperature optimization of ultra-high temperature ceramic components: Flexural strength testing and residual stress analysis. Ceram Int 2015, 41: 5085-5092.

[28] Meng S, Liu G, Guo Y, et al. Mechanisms of thermal shock failure for ultra-high temperature ceramic. Mater Design 2009, 30: 2108-2112.

[29] Zhang X, Wang Z, Hong C, et al. Modification and validation of the thermal shock parameter for ceramic matrix composites under water quenching condition. Mater Design 2009, 30: 4552-4556.

[30] Zimmermann JW, Hilmas GE, Fahrenholtz WG. Thermal shock resistance of $\mathrm{ZrB}_{2}$ and $\mathrm{ZrB}_{2}-30 \%$ SiC. Mater Chem Phys 2008, 112: 140-145.

[31] Wang Z, Hong $\mathrm{C}$, Zhang $\mathrm{X}$, et al. Microstructure and thermal shock behavior of $\mathrm{ZrB}_{2}-\mathrm{SiC}$-graphite composite. Mater Chem Phys 2009, 113: 338-341.

Open Access The articles published in this journal are distributed under the terms of the Creative Commons Attribution 4.0 International License (http://creativecommons. org/licenses/by/4.0/), which permits unrestricted use, distribution, and reproduction in any medium, provided you give appropriate credit to the original author(s) and the source, provide a link to the Creative Commons license, and indicate if changes were made. 